\title{
An Innovative Preparatory Program For Medicine in the UST Faculty of Medicine and Surgery
}

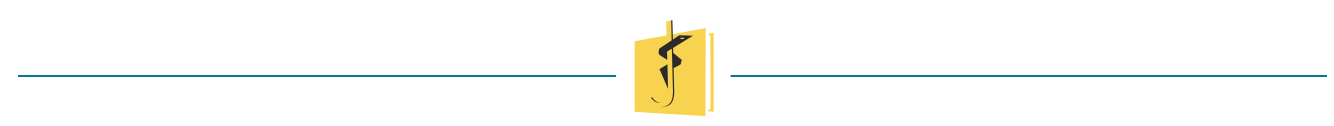

\author{
Ma. Lourdes P. Domingo - Maglinao, MD
}

The UST Faculty of Medicine and Surgery is at the threshold of its 150th Foundation Year in the coming 2021. The ground is shaking beneath our feet and its strong leadership felt that the time is ripe for educational innovation in the medical curriculum. With a shared understanding of the reasons behind the need for change, its committed staff undertook the challenge to implement the LEAPMed (Learning Enhanced Accelerated Program For Medicine) Program, a 2-year and two-special-term preparatory program for medicine.

Regarded as a premier institution of higher learning in Southeast Asia, the University of Santo Tomas, Faculty of Medicine and Surgery (UST-FMS) has continued to evolve and adjust to the changing needs of health care as well as the reshaping and transformation of medical education and real-world training.

In a survey conducted among the top medical schools in Asia, Oceania, and Europe, it is noted that the Philippine medical schools pattern their education after the American system. Compared to other Asian countries, the Philippines will take two years more to complete a medical degree. More important to note is the Philippine Medical Act of 1959, which requires a baccalaureate degree prior to entry into the medical education program.

As the center of innovative medical education in the country, we like to bring forth a premedical program that is shortened, considering the addition of two years in senior high school, and fo- cused on the basic human studies to form a strong and robust foundation when they enter the medical education program.

The scheme and concept of developing a distinct, innovative, yet focused and well-defined preparatory program for medicine, the Bachelor of Science in Basic Human Studies (BS BHS) or otherwise called the LEAPMed that will be implemented by no less than the Faculty of Medicine and Surgery was thought of in early 2015. With the current addition of two years of senior high school offering science-specific strands, we now see more equipped and mature students who are ready to face the academic demands of a shorter preparatory program for a medical degree. In December 2016, creation of a program under the Faculty of Medicine and Surgery began with the following primary considerations: (1) to come up with a pre-med program that will provide a more concise path to medicine proper, but of a shorter duration than any existing pre-med program, (2) inclusion of basic courses in medicine as part of the curriculum, thus providing a robust foundation, (3) applicants must be graduates of senior high school - Health Allied and STEM track, (4) limit the number of students to less than 100 for close supervision and monitoring of students' progress, (5) students will use the facilities and resources of the UST-FMS, (6) core teaching faculty will be from the Faculty of Medicine and Surgery, and (7) graduates of the program will continue the medical education program with the 
mainstream pathway at the UST-FMS upon completion of all requirements.

Eventually, a curriculum that is unique, competitive, and responsive to the changing needs of the society was formulated. The result is a two-year and two-special-term program devoted to the understanding of basic human sciences. The program is focused on human sciences more than any other premedical course. At the end of the program, students will exhibit proficiency in the basic human sciences and exemplify readiness to pursue medical studies. Students will graduate with a degree of BS BHS as required by the Medical Act of 1959. After completion of all requirements which includes taking the NMAT, the students will be eligible for admission to medicine proper at the UST-FMS.

Approval of the program had to pass several approving bodies in the university namely: the Academic Senate, the Council of Regents, and the Board of Trustees. Because of the university's autonomous status and the program being compliant with the statutes of the Medical Act of 1959 and the CHED Memorandum Order 18 Series of 2016, the LEAPMed was finally approved to commence from the academic year 2018-2019.

The program is offered to a limited number of highly exceptional students and completely under the supervision of the Faculty of Medicine and Surgery. From the thousands of applicants from all over the country, given the initial screening requirement of a general weighted average of 90 and coming from STEM or Health Allied Strand, these applicants were allowed to take the initial USTET examination with the LEAPMed segment. Ranking using the UST Predictive Scoring (derived from IQ, composite USTET score, and LEAPMed examination score) fur- ther reduced the number from thousands to the top 200 . From the results of the initial ranking, interview, and psychological test considered, the top 90 most eligible applicants were determined. They formed the first batch of BS BHS students of the university.

The program finally commenced in this special term of 2018-2019. On June 7, 2019, the freshmen were officially welcomed and given an orientation on the rules and policies of the university, the Faculty of Medicine and Surgery as well as the Basic Human Studies program. This was followed by a tour of the facilities by the students and a meeting of parents and faculty. The day culminated with a seminar on "Parenting" for the parents and guardians of BS BHS (LEAPMed) students, which was conducted by Life Coach Philippines.

We are optimistic that this accelerated and abbreviated program will succeed, given the tedious selection process for applicants, the focused curriculum, the close monitoring of students, and the periodic evaluation of the curriculum. The program is envisioned to provide the best premedical cum medical program to highly qualified students.

(i) Open Access This article is licensed under a Creative Commons Attribution 4.0 International License, which permits use, sharing, adaptation, distribution and reproduction in any medium or format, as long as you give appropriate credit to the original author(s) and the source, provide a link to the Creative Commons license, and indicate if changes were made. The images or other third party material in this article are included in the article's Creative Commons license, unless indicated otherwise in a credit line to the material. If material is not included in the article's Creative Commons license and your intended use is not permitted by statutory regulation or exceeds the permitted use, you will need to obtain permission directly from the copyright holder. To view a copy of this license, visit http://creativecommons.org/licenses/ by $/ 4.0 /$. 